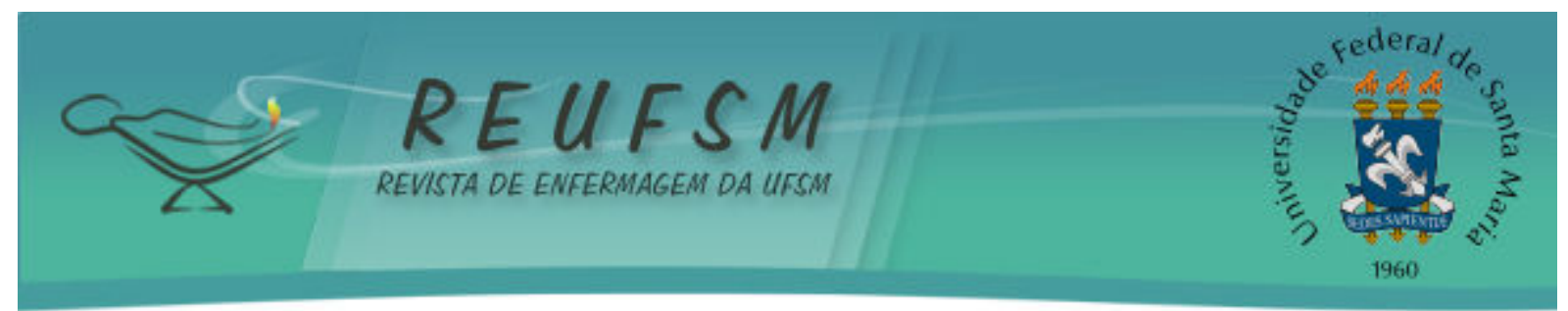

EDITORIAL

\title{
O CUIDADO AO PARTO E NASCIMENTO: IMPLICAÇÕES SOB A ÓTICA FENOMENOLÓGICA DE HUSSERL
}

\section{CARING AT DELIVERY AND BIRTH: IMPLICATIONS FROM THE PHENOMENOLOGICAL PERSPECTIVE OF HUSSERL}

\section{LA ATENCIÓN AL PARTO Y NACIMIENTO: IMPLICACIONES DESDE LA PERSPECTIVA FENOMENOLÓGICA DE HUSSERL}

Valdecyr Herdy Alves ${ }^{1}$

\section{Doi: $10.5902 / 2179769216466$}

Articular o cuidado ao parto e nascimento com a crise das ciências europeias descrita por Husserl, é reafirmar a crise que vivemos na saúde brasileira, em especial no que tange à saúde sexual e reprodutiva das mulheres, cujo cuidado tem demandado a utilização de alta tecnologia, às vezes até desnecessariamente. "Nascer, no Brasil, não tem sido uma experiência natural nem para pobres nem para ricos. $O$ parto vaginal, mais frequente nos estabelecimentos públicos, quase sempre ocorre com muita dor e excesso de intervenções". ${ }^{1}$

Refletir a respeito é ir ao encontro das seguintes indagações de Husserl: qual o sentido desta matematização da natureza? Como reconstruímos o curso do pensamento que a motiva? ${ }^{2: 37} 0$ que ele pretende, na verdade, é questionar o que está presente na atualidade, ou seja, o fazer das ciências sem lançar um olhar ao pré-científico indutivo que possibilite ir às coisas mesmas; perceber as instituições de sentido que norteiam o processo de construção do pensar científico que envolve uma ciência do cuidado em saúde, ciência essa cuja essência mais originária deve ser procurada no mundo da vida (Lebenswelt).

A objetivação e a racionalização das ciências, de acordo com Husserl, tem se fortalecido no campo dos fatos como forma quantificável para a realização das ciências, no caso presente a ciência do cuidado ao parto e nascimento, corroborando o pensamento do autor no sentido de que "esta concepção de natureza pela qual a idéia científica de uma regulação universal dos conhecimentos do mundo e, em especial, dos acontecimentos físicos, assume um sentido de universo calculável". 2:353

Nesse sentido, os valores, crenças, emoções, o próprio mundo da vida das mulheres em processo de parturição, são meros epifenômenos que não fazem parte da realidade cotidiana do cuidado ao parto e nascimento. Essa orientação lógica institui um processo de naturalização da investigação científica; quantifica, mas não reconhece as experiências subjetivas como originárias da própria vida.

A ciência que proclama o cuidado ao parto e nascimento vem sendo instituída no campo tecnocrático rotineiro, porém, reconhecendo o parto como um evento patológico que resulta na tecnificação do cuidado, isto é, um parto dirigido, instrumentalizado, ${ }^{3}$ o que significa, para Husserl, a problematização das ciências matematizadas, aquelas que não reconhecem a subjetividade como campo da ciência do mundo originário vivido pelos sentidos de cada indivíduo no seu ser-aí nesse mundo. Assim, "o método produzido, 0 cumprimento progressivo da tarefa é como método ... mas sem o sentido afetivo". 2:71

Pensar na Fenomenologia de Husserl e nas suas interfaces com os dias atuais, revela que vivemos constantemente a necessidade da "elucidação do sentido da origem da ciência moderna da natureza ... deslocamento de sentido ... numa espécie de círculo... a 


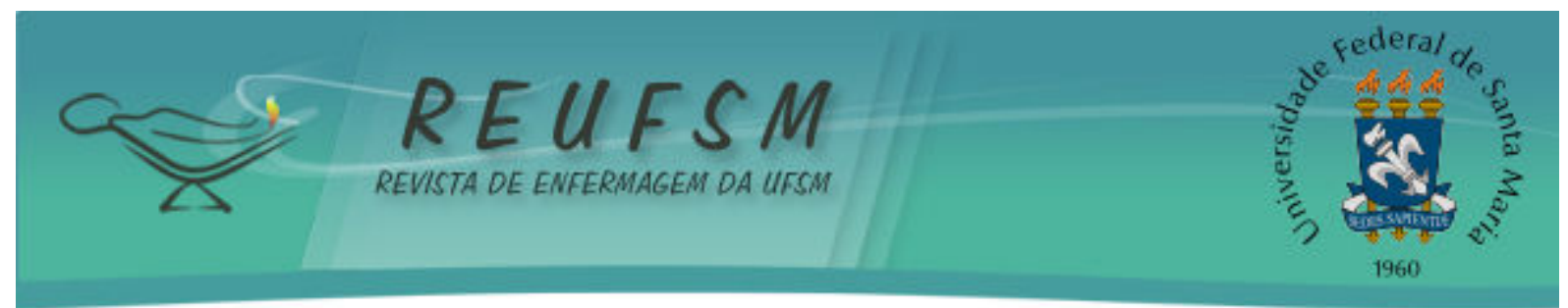

${ }^{1}$ Doutor em Enfermagem. Professor Titular do Departamento Materno-Infantil e Psiquiátrico da Escola de Enfermagem Aurora de Afonso Costa (EEAAC) da Universidade Federal Fluminense (UFF). Rio de Janeiro, Brasil. E-mail: herdyalves@yahoo.com.br

compreensão do início só se pode alcançar por inteiro a partir das ciências dadas na sua figura hodierna, no olhar retrospectivo para o seu desenvolvimento". 2:73 Assim, a crise que Husserl destaca deve chamar nossa atenção para uma análise crítica e reflexiva, porque está nos campos da vida, da filosofia, da ciência e da ética humana.

Husserl $^{2}$ reforça que não se deve negar a razão, mas olhar para as ciências a partir do mundo da vida, das experiências sensíveis e da subjetividade, que são sentidos originários das ciências modernas, portanto, possibilitando uma reflexão crítica e humana no campo da saúde. Esses são os desafios que se apresentam para os profissionais de saúde, para os formadores em saúde e para as políticas de saúde no campo do parto e nascimento.

Husserl $^{2}$ alerta ainda para uma crise globalizada, na qual a razão técnica, científica, descolada do mundo da vida, puramente objetiva, que não reconheça o mundo de experiências subjetivas vivida pelas mulheres em processo de parturição, não resultará em mudanças que favoreçam o quadro epidemiológico do parto e nascimento no Brasil.

\section{REFERÊNCIAS}

1. Leal MC, Gama SGN. Nascer no Brasil. Cad Saúde Pública [Internet]. 2014;30 Supl 1;S5S7. ISSN 0102-311X. http://dx.doi.org/10.1590/0102-311XED01S114.

2. Husserl E. A crise das ciências europeias e a fenomenologia transcendental: uma introdução à filosofia fenomenológica. Tradução de Diogo Falcão Ferrer, direção científica Pedro M. S. Alves. Lisboa: Phainomenon, Centro de Filosofia da Universidade de Lisboa; 2008.

3. Rabelo LR, Oliveira DL. Percepções de enfermeiras obstétricas sobre sua competência na atenção ao parto normal hospitalar. Rev Esc Enferm USP [Internet]. 2010;44(1):213-20. ISSN 0080-6234. http://dx.doi.org/10.1590/S0080-62342010000100030. 